\title{
Spectrophotometric Methods for the Estimation of Isoxsuprine Hydrochloride in Bulk and Oral Dosage Form
}

\author{
Sekar A $\mathrm{M}^{3}$, Jerad Suresh $\mathrm{A}^{2}$ and Niraimathi. $\mathrm{V}^{1^{*}}$ \\ Department of Pharmaceutical Chemistry, College of Pharmacy, \\ Madras Medical College, Chennai-600003, Tamil Nadu, India.
}

\begin{abstract}
Four new, simple, sensitive and reproducible spectrophotometric methods have been developed for the estimation of isoxsuprine hydrochloride in tablet dosage form. Method A involves the determination of isoxsuprine hydrochloride by Q-absorbance ratio method at $269 \mathrm{~nm}$ and $274 \mathrm{~nm}$; the Beer's concentration range was found to be 20-100 $\mu \mathrm{g} / \mathrm{mL}$. Method $B$ and Method $C$ involves the determination of isoxsuprine hydrochloride by first derivative spectrophotometry and second derivative spectrophotometry respectively. The normal spectrum was derivatized to first and second order derivative spectrum and the linearity was found to lie within the Beer's range for isoxsuprine hydrochloride. Method D involves the determination of isoxsuprine hydrochloride by Area under curve method (AUC) and the linearity was established. The correlation coefficient for all the four methods were found to be 0.999 and the developed methods were analyzed for specificity, limit of detection (LOD), limit of quantification (LOQ), linearity of response, precision and accuracy. Thus the proposed methods could be adopted for routine analysis of bulk drug and its formulation.
\end{abstract}

Keywords: Area under curve (AUC), Beer's law, Derivative Spectrophotometry, Isoxsuprine hydrochloride, $Q$-Absorbance ratio

\section{Introduction}

Isoxsuprine $^{1}$ (ISX), 4-Hydroxy- $\alpha-[1-[(1-$ methyl-2-phenoxy-ethyl)amino]ethyl benzenemethanol, is a vasodilator that produces the effects of $\beta$-adrenoreceptor stimulation and $\alpha$-adrenoreceptor antagonism; the former effect is more predominant. It is used in the treatment of cerebral and peripheral vascular diseases. It is also used to arrest premature labour. Several analytical methods (colorimetric methods ${ }^{2}$, MS-MS identification ${ }^{3}$ in post administration equine urine) have been reported for the determination of isoxsuprine hydrochloride in raw material, dosage forms and biological fluids ${ }^{4}$. Literature survey revealed that few sophisticated analytical methods have been reported for the estimation of isoxsuprine hydrochloride. The present work aims to device four novel methods by UV -Vis-spectrophotometry which has not been reported till date.

\section{Experimental Methods}

\subsection{Instrumentation}

All spectral measurements were made on Shimadzu UV-Vis-spectrophotometer 1650 with $1 \mathrm{~cm}$ matched quartz cell. All the solutions were freshly prepared with distilled water.

\subsection{Preparation of Standard stock solution}

It was prepared by dissolving $100 \mathrm{mg}$ of drug in $100 \mathrm{~mL}$ standard flask and the volume was made up with water to produce $1000 \mu \mathrm{g} / \mathrm{mL}$.

\subsection{Preparation of Sample solution}

The average weight 20 Tablets of isoxsuprine hydrochloride was weighed and finely powdered. The powder equivalent to $10 \mathrm{mg}$ of isoxsuprine hydrochloride was taken in a $100 \mathrm{~mL}$ volumetric flask and shaken with water to dissolve the active ingredient and made up the volume to produce $100 \mu \mathrm{g} / \mathrm{mL}$. The solution was then filtered, first few $\mathrm{ml}$ of the filtrate was discarded and the filtrate was used for further analysis.

\subsection{Assay}

\subsubsection{Method A: Q-Absorbance Method}

Q-Absorbance method depends on the property that, for a substance which obeys Beer's law at all wavelengths, the ratio of absorbance at any two wavelengths is a constant value independent of concentration or path length. The wavelengths selected for this method are $269 \mathrm{~nm}$ and $274 \mathrm{~nm}$. The ratio of absorbance between these two wavelengths was calculated the difference in absorbances between their two wavelengths were calculated and plotted against concentration to determine the linearity; the concentration of sample was 
determined by interpolation. The values obtained by the proposed method are represented by calibration graph (fig-1).

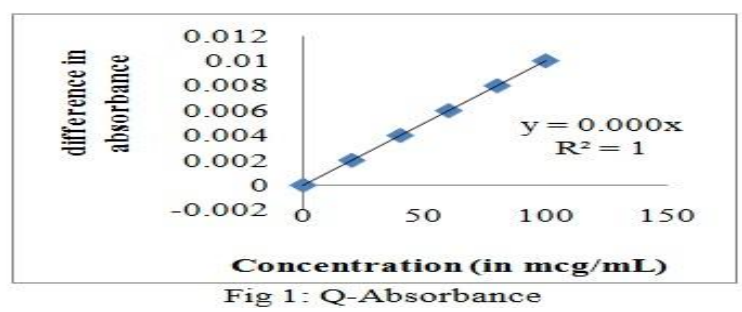

\subsubsection{Method B: First order derivative ${ }^{6}$}

The standard stock solution of isoxsuprine hydrochloride was suitably diluted to give varying concentration ranging from $20-100 \mu \mathrm{g} / \mathrm{mL}$. The solutions were scanned in the range of $200-400 \mathrm{~nm}$ and the primary spectrum was then derivatized to first order using derivative mode. The first derivative $\left(D^{1}\right)$ spectrum is the plot of the rate of change of absorbance with wavelength against wavelength i.e., the plot of the slope of the fundamental spectrum against wavelength or $\mathrm{dA} / \mathrm{d} \lambda$ vs. $\lambda$. The amplitude of the negative peak maximum at the zero crossing of the first order curve was measured in $\mathrm{mm}$ at $274 \mathrm{~nm}$. A calibration graph was obtained by plotting concentration versus amplitude. The sample solution was suitably diluted to get a concentration between $20-100 \mu \mathrm{g} / \mathrm{mL}$ and the same procedure was adopted. The amplitude obtained for the sample was then interpolated on the calibration graph and the concentration of isoxsuprine hydrochloride in the sample was then determined. The overlain spectrum for this method is shown in (fig-2).

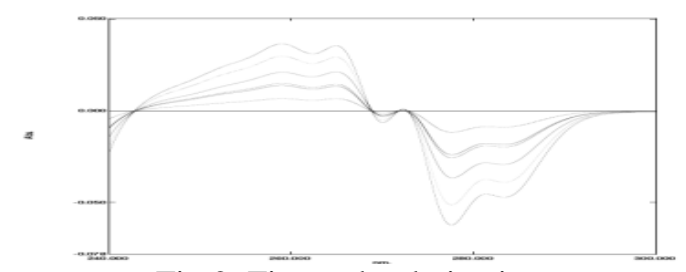

Fig 2: First order derivative

\subsubsection{Method C: Second order derivative: ${ }^{7}$}

The fundamental spectrum obtained for the above was then derivatized for the second order. The amplitude of the negative peak maximum was measured in $\mathrm{mm}$ at $274 \mathrm{~nm}$. The respective overlain spectra is shown in (fig-3).

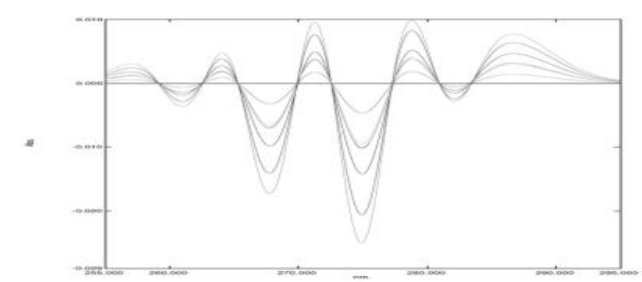

Fig 3 : Second order derivative

\subsubsection{Method D: Area under the curve ${ }^{8}$}

The AUC (area under curve) method involves the calculation of integrated value of absorbance with respect to the wavelength between the two selected wavelengths $\lambda 1$ and $\lambda 2$. The wavelength range is selected on the basis of repeated observations so as to get the linearity between area under curve and concentration.. The AUC for isoxsuprine hydrochloride (fig 4) was determined between 245 and $290 \mathrm{~nm}$ for both standard and sample. The calibration graph was plotted between AUC and concentration. The sample AUC was interpolated on the respective linearity chart of the AUC and the sample concentration was determined.

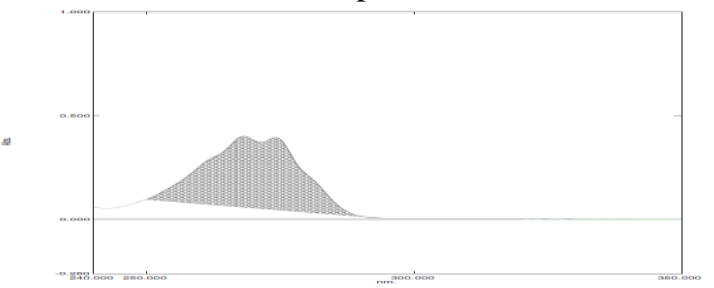

Fig-4: Area under the curve(AUC) 


\section{Recovery Studies}

The recovery studies were carried out on spiked samples by adding predetermined amount of standard drugs to the respective sample. About 20, 40 and 100\% of standard drugs were added to the sample solutions and the absorbance was measured. The percentage recovered was calculated. The recovery study was performed at three levels to confirm the precision and accuracy of the above said methods.

\section{Results And Discussions}

Isoxsuprine hydrochloride was found to obey Beer's law in the concentration range of $20-100 \mu \mathrm{g} / \mathrm{mL}$. Isoxsuprine hydrochloride showed good linearity as indicated by correlation coefficient value of 0.999 . The optical parameters of isoxsuprine hydrochloride with respect to all the three methods are presented in table no.1. The percentage of the individual drugs in the formulation according to the four methods were calculated and represented in the table no.2.

\subsection{TABLE 1: Optical Parameters Of Isoxsuprine Hydrochloride By Uv Spectrophotometry}

\begin{tabular}{|c|c|c|c|c|c|}
\hline S.No & Parameters & $\begin{array}{c}\text { Method A } \\
\text { (Q- } \\
\text { absorbance) }\end{array}$ & $\begin{array}{c}\text { Method B } \\
\text { (First } \\
\text { derivative } \\
\text { spectroscopy) }\end{array}$ & $\begin{array}{c}\text { Method C } \\
\text { (Second } \\
\text { derivative } \\
\text { Spectroscopy) }\end{array}$ & $\begin{array}{c}\text { Method D } \\
\text { (Area under } \\
\text { Curve) }\end{array}$ \\
\hline 1 & $\begin{array}{c}\text { Wavelength range } \\
(\mathrm{nm})\end{array}$ & $274 \mathrm{~nm}$ & $274 \mathrm{~nm}$ & $274 \mathrm{~nm}$ & $274 \mathrm{~nm}$ \\
\hline 2 & $\begin{array}{c}\text { Beer's law limit } \\
\left(\mu \mathrm{g} / \mathrm{mL}^{-1}\right)\end{array}$ & $20-100$ & $20-100$ & $20-100$ & $20-100$ \\
\hline 3 & $\begin{array}{c}\text { Regression equation } \\
(\mathrm{y}=\mathrm{mx}+\mathrm{c})\end{array}$ & $0.00 \mathrm{x}+0.00$ & $0.791 \mathrm{x}-0.238$ & $1.077 \mathrm{x}+0.476$ & $126.7 \mathrm{x}+152.6$ \\
\hline 4 & Slope( m) & 0.000 & 0.791 & 1.077 & 126.7 \\
\hline 5 & Intercept $(\mathrm{c})$ & +0.000 & -0.238 & +0.476 & +152.6 \\
\hline 6 & $\begin{array}{c}\text { Correlation } \\
\text { coefficient }\end{array}$ & 1.0 & 0.999 & 0.999 & 0.999 \\
\hline 7 & $\begin{array}{c}\text { Sandell's sensitivity } \\
(\mu \mathrm{g} \text { cm } / 0.001 \mathrm{~A} \\
\mathrm{unit})\end{array}$ & 0.061224 & --------- & -------- & -------- \\
\hline 8 & LOD $(\mu \mathrm{g} / \mathrm{mL})$ & ------- & -4.15094 & 6.1682 & 16.9983 \\
\hline 9 & LOQ $(\mu \mathrm{\mu g} / \mathrm{mL})$ & -------- & -12.5786 & 18.6915 & 51.51028 \\
\hline
\end{tabular}

\subsection{TABLE 2: RESULT OF TABLET ASSAY}

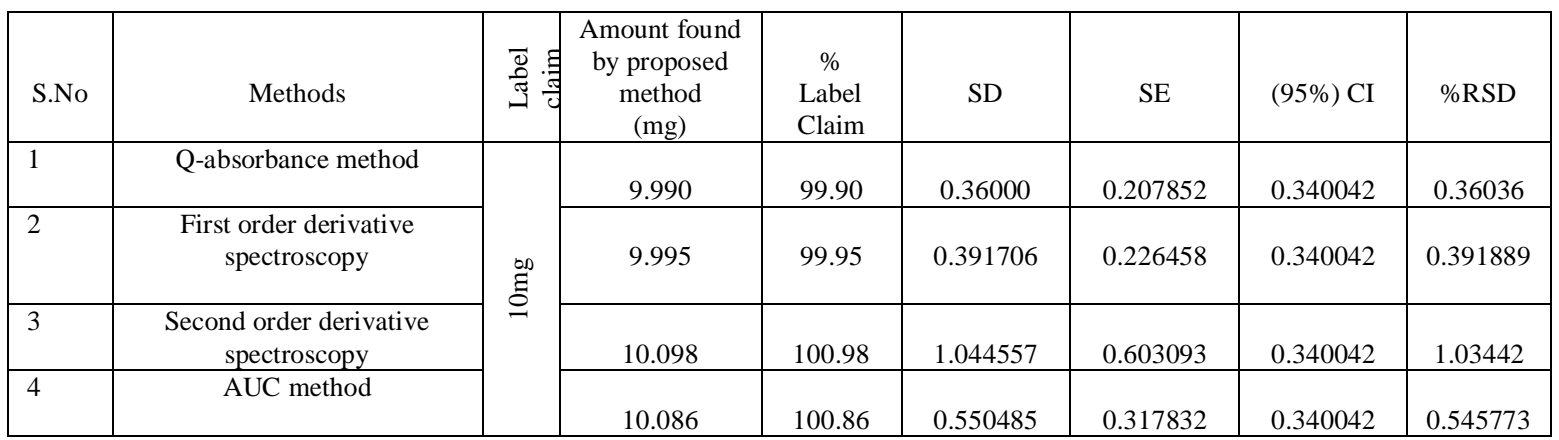

Each value is a mean of 3 determination

The results of the analysis showed that the amount of drugs were in good agreement with the label claim of the formulation. The accuracy of the proposed method were determined by recovery studies. The recovery studies were carried out on spiked samples and calculated for all the three methods. The percentages recovered were found to be in the range of $99-102 \% \mathrm{w} / \mathrm{w}$ ( table.3) which showed that the excipients in the formulation did not interfere with the analysis 


\subsection{TABLE 3: RECOVERY STUDIES}

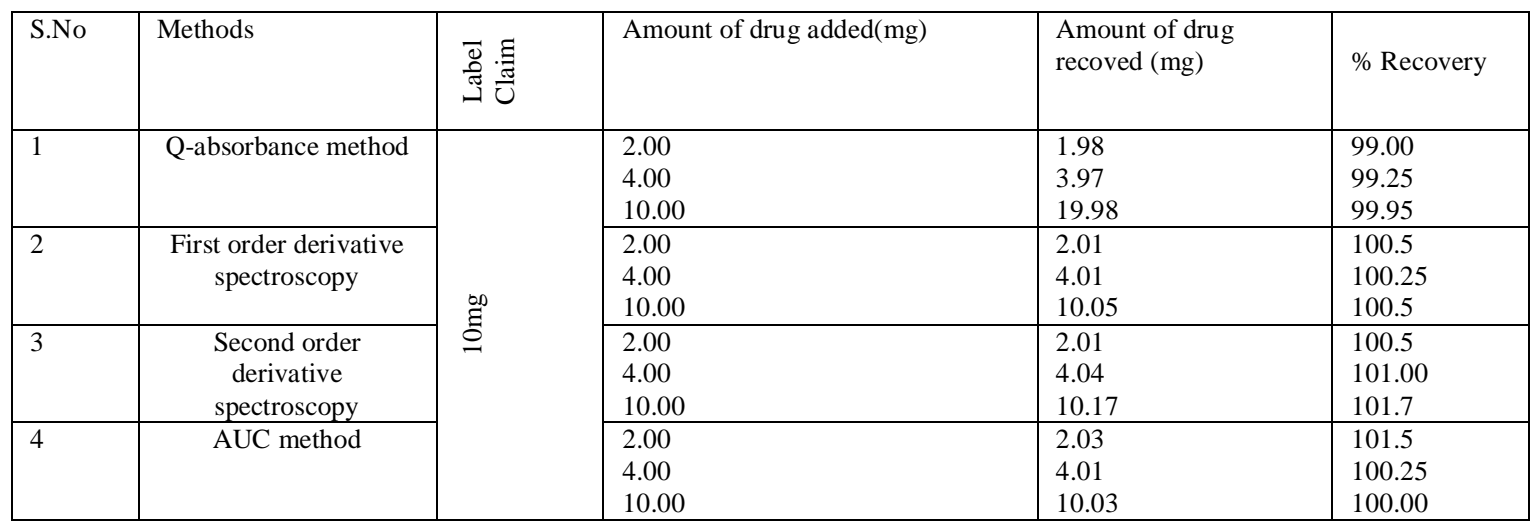

Each value is a mean of 3 determinations

\section{Conclusion}

The percentage recovery of all the four methods lies between $99-102 \% \mathrm{w} / \mathrm{w}$. The correlation coefficient for all the four methods are 0.999 and the recovery studies indicates that there is no interference of other ingredients present in the formulation. Thus, these four methods are simple, precise, accurate, less time consuming and could be used for routine analysis.

\section{Acknowledgement}

The authors are thankful to the Department of Pharmaceutical Chemistry, College of Pharmacy, Madras Medical College for rendering full support to carry out the study.

\section{REFERENCES}

[1] Kalsang k Tharpa , kanakapura k basavaiah, Hosakere Doddarevanna HD Revanasiddappa, kanakapura Basavaiah KB Vinay ,Spectrophotometric determination of isoxsuprine hydrochloride using 3-methyl-2-benzothiazolinone hydrazone hydrochloride in spiked human urine. Pubmed 81 (4-5):1216-23 i5 Jun 2010.

[2] Revanasiddappa HD,Manju BG Spectrophotometric determination of ritodrine and isoxsuprine hydrochlorides using 4aminoantipyrine. Journal of AOAC International [2000, 83(6):1440-5]

[3] J M Bosken, A F Lehner, A Hunsucker, J D Harkins, W E Woods, W Karpiesiuk, W G Carter, J Boyles, M Fisher, andT Tobin Direct MS-MS identification of isoxsuprine -glucuronide in post administration equine urine.Arzneimittelforschung,2010 : 60(7):415-20.

[4] J.M. Bosken ${ }^{\dagger}$, A.F. Lehner, C.G. Hughes, W.E. Woods, F.C. Camargo,J.D. Harkins,J. Boyles,T. Tobin A GC-MS Method for the Determination of Isoxsuprine in Biological Fluids of the Horse Utilizing Electron Impact Ionization

[5] Priyadarshini J, Giji GP, Niraimathi V, Jerad Suresh A UV spectrophotometric estimation of metaxalone in bulk and tablet dosa ge form. Int. Journal of Chemical Sciences 2010; 8(2):1041-1045.

[6] Niraimathi V, Jerad Suresh A, Nanjappan K Spectrophotometric estimation of Nislodipine in bulk and tablet dosage formulation. Acta Ciencia Indica 2010; xxxvi C(4):393.

[7] Pharmacopeia: Vol 2;2010. p.1527-1529s

[8] Jeffery GH, Bassett J, Mendham J and Denney RC. Vogel's Textbook of Quantitative Chemical Analysis. Fifth edition, New York, Longman Scientific \& Technical with John Wiley \& Sons, p 668-670.

[9] Beckett AH and Stenlake JB. Practical Pharmaceutical Chemistry. Part two. Fourth edition, New Delhi, CBS publisher., p 296-300.

[10] Smita T.Kumbhar, Swapnil D. Jadhav, Neela M. Bhatia, Manish S. Bhatia. Development and validation of derivative spectrophotometric method for estimation of atorvastatin calcium and amlodipine besylate in tablet dosage form. Int $\mathrm{J}$ Pharmacy and Pharm Sci 2011; 3(4): 195-197.

[11] Gurdeep R Chatwal and Sham K Anand. Instrumental Methods of Chemical Analysis. Fifth edition, Hyderabad, Himalaya publishing house, p 2.178 